\title{
SUJEITO LABORANS: UMA NARRATIVA SOBRE A IDENTIFICAÇÃO DO SUJEITO DA PSICANÁLISE CONFRONTADO PELO TRABALHO
}

\author{
Bruno Costa Alvares ${ }^{1 *}$ \\ Kamayra Gomes Mendes ${ }^{2} * *$
}

\section{RESUMO}

A pesquisa pretende fazer uma narrativa, à luz da teoria de Jacques-Alain Miller, sobre o sujeito em dialética com as formas jurídicas do trabalho. Considerando a dinâmica social transpassada pela mercantilização, buscou-se uma elucidação sobre a formação e relação do sujeito com a linguagem e o 'Outro', não concebida no entendimento do sujeito de direito tradicional. Como resultado, notou-se que a desconsideração da subjetivação do trabalhador é uma lacuna no mundo jurídico, que viabiliza sua reiterada sujeição e descaracteriza a proteção ao seu trabalho.

Palavras-chave: Psicanálise; Sujeito; Linguagem; Trabalho; Jacques-Alain Miller.

\section{LABORANS' SUBJECT: A NARRATIVE ABOUT THE IDENTIFICATION OF THE PSYCHOANALYSIS' SUBJECT AND ITS CONFRONTATION WITH LABOUR}

\begin{abstract}
The work intends to present a narrative, in the light of Jacques-Alain Miller's theory, about the subject of psychoanalysis in dialectics with legal forms of labor. Considering the social dynamics permeated by commodification, we sought an elucidation about the formation and relation of the subject with language and the 'Other', not conceived in the understanding of the subject of traditional law. As a result, it was noted that the disregard of the worker's subjectivation is a gap in the legal world, which makes possible his repeated subjection and mischaracterizes the protection of their work.
\end{abstract}

Key words: Psychoanalysis; Subject; Language; Labor; Jacques-Alain Miller.

\section{INTRODUÇÃO}

Muitas são as discussões sobre o sujeito na/da psicanálise. É um recorte, alienado da estrutura, um falta-a-ser ou um conceito filosófico? Existe de forma individual ou é efeito da cadeia de significantes, articulado ao Outro? Perguntar-se sobre esse sujeito é um trabalho de exploração das entrelinhas e possibilidades, à margem do pensamento institucional estratificado, processo que não leva a conclusões sintéticas.

\footnotetext{
* Mestrando no Programa de Pós-graduação em Direito da Universidade Federal do Paraná. Rua Visconde do Rio Branco, 1358. Centro. Curitiba. Paraná. 80.420-210. E-mail: brunoalvares.ba@gmail.com.

** Mestranda no Programa de Pós-graduação em Direito da Universidade Federal do Paraná. Rua Hilário Moro, 526, Tingui, Curitiba, Paraná, 82.600-030. E-mail: kamayramendes@gmail.com.
} 
$\mathrm{Na}$ experiência de pesquisa, a diferença constitutiva entre o desejo de querer dizer algo e o que se diz, típica da vivência da análise clínica, é por vezes um incômodo. Nos moldes lacanianos, contudo, o bem-dizer não se trata de dizer diretamente o que se quer, mas saber fazer o possível com a metonímia, a alusão, dizer a verdade à metade, pois pretender dizer toda a verdade tende a se converter em mentira (MILLER, 1995, p. 43). Assim, o objetivo da pesquisa é propor uma narrativa sobre o sujeito de trabalho que considere a órbita de exclusões verificadas na estrutura jurídica tradicional.

Para isso, foi necessário questionar as distinções do sujeito de direito clássico para o sujeito da psicanálise e quais contribuições autores como Jacques-Alain Miller poderiam apresentar para formas-outra de visualizar o problema, afinal, o que está sendo excluído da análise do direito aos processos de formação e reprodução das sujeições trabalhistas em um contexto de mundialização do capital?

A formulação de uma proposta de resposta a tais perguntas exigiu a consulta a diversas fontes bibliográficas, de forma dedutiva e qualitativa, dada a necessidade de compreensão dos principais conceitos da psicanálise para então relacioná-los, ao fim, com a dinâmica trabalhista.

Desta forma, respeitando o entendimento lacaniano de que a psicanálise e a ciência se encontram na figura do sujeito, este trabalho inicialmente apresentou as bases para a identificação do sujeito da psicanálise, a partir da descoberta do inconsciente, traçando imediações nas teorias de Freud e Lacan. Posteriormente, entendeu-se necessário realizar a identificação, na obra de Miller, da estrutura do sujeito, sua relação com o 'Outro', e da estruturação desse sujeito como linguagem (o que nos permitirá abordar, mesmo que de forma elucidativa, a clínica psicanalítica-lacaniana). Por fim, realizou-se uma confrontação do sujeito com o mundo do trabalho, desdobrando a partir daí as consequências da identificação e expressão desse sujeito em uma sociedade mercantilizada.

\section{CONSTITUIÇÃO E ESTRUTURA DO SUJEITO DA PSICANÁliSE}

Para situar a descoberta do inconsciente na história da Europa moderna, Freud apresenta a ideia das três doenças narcísicas representadas por três humilhações sucessivas sofridas pelo homem (ŽIŽEK, 2010, p.8). Primeiro, Copérnico demonstrou que a terra gira em torno do sol, retirando-a do centro do universo e privando-nos, seres humanos, desse lugar central. Segundo, Darwin demonstrou que não emergimos da evolução cega, retirando o 
homem do centro da criação. Terceiro, a psicanálise descentralizou o homem de si mesmo ao mostrar que "o $e u$ não é senhor nem mesmo em sua própria casa". Nesse sentido, ao retirar a centralidade da consciência como lugar do sujeito, o inconsciente freudiano subverteu de modo radical o cogito cartesiano e introduziu a dimensão de uma racionalidade inteiramente nova (COUTINHO JORGE, 2005, p. 17).

Diante do "progresso" da ciência, o homem viu-se confrontado pela perda do controle de si e do controle do outro ${ }^{3}$. E, no mesmo sentido, os últimos avanços científicos parecem infligir uma série de humilhações adicionais à imagem narcísica do homem, eis que nossa mente é uma mera máquina de calcular e reproduzir e nosso senso de liberdade e autonomia é fruto de mera ilusão.

A descoberta do inconsciente, para além de representar uma doença narcísica, emerge como uma nova possibilidade de racionalização na ciência. Possibilitou o surgimento de um novo paradigma (do inconsciente) e abriu as portas para revelação de um ator até então desconhecido, o sujeito.

Da identificação e caracterização do homem moderno, com suas exigências de individualidade e autonomia, Lacan percebe a possibilidade de mostrar como a constituição do Eu desse homem moderno coloca em funcionamento uma dinâmica de identificação e de desconhecimento da própria paranoia (SAFATLE, 2018, p. 31). Por isso, a cura, para Lacan, está ligada à uma certa dissolução do Eu, a uma "experiência no limite da despersonalização" (LACAN, 2005, p.53), e nessa exposição do caráter paranóico do Eu pode se encontrar a teoria que Lacan denomina de estádio de espelho.

É a partir do estádio do espelho, momento inaugural de constituição do eu, portanto, que Lacan introduz uma distinção própria entre o eu e o sujeito feita a partir da distinção entre o simbólico e o imaginário. Essa distinção se dá porque a formação do Eu depende fundamentalmente de um processo ligado à constituição da imagem do corpo próprio (SAFATLE, 2018, p. 31). Assim, se o Eu é da ordem do imaginário e do sentido (já que, para se constituir, o Eu aproveita uma imagem que, no fundo, não é ele mesmo, mas um outro, no espelho), o sujeito é partido entre os significantes do simbólico. Deste modo, a unidade obtida

3 Importante destacar a diferença substancial, já neste ponto, entre 'outro' e 'Outro'. Como bem elucida Safatle, os 'outros' são fundamentalmente outros empíricos que são visíveis diante de mim em todo processo de interação social, ao passo que o 'Outro' é o sistema estrutural de leis que organizam previamente a maneira como o 'outro' pode aparecer para mim. 'outro' diz respeito aos fenômenos, 'Outro' diz respeito à estrutura. O primeiro está submetido ao segundo (SAFATLE, 2018, p. 47). 
no eu não o é jamais no nível do sujeito, eis que este é sempre dividido, conflitivo e impossível de ser identificado em absoluto.

Autonomia e individualidade, atributos essenciais à noção moderna do Eu, mostramse apenas como figuras do desconhecimento em relação a uma dependência constitutiva ao 'Outro'. E essa noção é tão forte que faz com que Lacan defina que a verdadeira função do Eu não está ligada à síntese psíquica ou à síntese das representações, mas ao desconhecimento da sua própria gênese (SAFATLE, 2018, p. 35).

Essa passagem da descoberta do inconsciente à denotação do Eu é fundamental para a compreensão da dualidade criada por Lacan entre moi e Je para dirimir a constituição do sujeito. Se o Eu é o resultado de um processo social de identificação, então apenas seria possível falar em alienação de si se aceitar a existência de algo, no interior de si mesmo, que não é o Eu. Esse algo se apresenta como uma certa essência recalcada pelo advento do Eu, e é neste si mesmo estranho ao Eu aquilo que Lacan chama de sujeito, lugar do desejo. E aí surge a dualidade criada por Lacan entre moi, que representa o Eu produzido pela imagem do corpo, e $J$, o sujeito do desejo. É por essa dualidade que Lacan fala em uma discordância primordial entre Eu (moi) e o ser (do sujeito) (SAFATLE, 2018, p. 37).

Se o sujeito é o lugar do desejo, a falta é elemento constitutivo desse sujeito. Nesse sentido, a falta caracterizada como um modo de ser do sujeito levará Lacan a falar do desejo como uma falta-a-ser. A negatividade do desejo lacaniano visa a elaboração de uma crítica ao caráter normativo de toda tentativa de construir relações de identidade imediata entre o desejo e seus objetos. O importante neste ponto é entender que não é a finitude que interessa a Lacan, mas a noção de que há algo no sujeito que só se manifesta de maneira negativa e essa negatividade faz emergir uma força de presença daquilo que desconhece imagem (SAFATLE, 2018, p. 39).

O sujeito da psicanálise é concebido como efeito da linguagem, o que modifica a articulação entre ser e pensamento. O sentido da articulação sai de um 'penso logo sou' para um 'eu sou onde não penso e penso onde não sou'. Com isso em consideração, é possível então falar dos processos de alienação e separação do sujeito, em sua formação, para com o Outro. (BARTIJOTO; TFOUNI e CHIARETTI, 2019, p. 8).

$\mathrm{Na}$ concepção lacaniana, a alienação constitui-se como processo de "escolha forçada" pela qual passam todos os sujeitos que almejam constituir sua subjetividade. Portanto, para sua formação, o sujeito precisa, necessariamente, para constituir-se, atrelar seu 
desejo ao Outro, pois somente e tão somente só assim poderá ser reconhecido pelo Outro e, em troca, constituirá a si.

A clínica lacaniana vai operar, portanto, através da reorientação da fala do sujeito. O trabalho analítico consiste em levar o sujeito a apreender as imagens que determinam sua relação a si mesmo e ao mundo. Essas imagens, contrações de tramas sociossimbólicas nas quais o sujeito se inseriu ao socializar seu desejo e apreensão será de certa forma uma rememoração da história natural das formas de captura do desejo (SAFATLE, 2018, p. 41).

Essa análise é responsável por mostrar como tais imagens eram a maneira desesperada do sujeito de dar forma a um desejo fundamentalmente opaco e desprovido de objeto. A análise é solidária a uma operação de dissolução do mundo dos objetos imaginários do desejo e, caracterizada como subjetivação da falta, representa a transformação de algo em modo de manifestação do sujeito (SAFATLE, 2018, p. 41).

\subsection{CONCEPÇÃO DE JACQUES-ALAIN MILLER SOBRE ESTRUTURA E SUJEITO}

Antes de adentrarmos ao cerne das ferramentas de manifestação do sujeito com a análise e a interação sociossimbólica com o direito do trabalho, um tópico próprio é essencial para entender o sujeito a partir das particularidades do pensamento de Jacques-Alain Miller, especificamente sobre a interação entre estrutura e construção do sujeito.

\subsubsection{Estrutura}

A psicanálise de matriz lacaniana modifica a teorização dos pressupostos dos estruturalistas clássicos e torna o inconsciente como condição da linguística. Herdeiro deste entendimento, Miller apresenta suas concepções sobre o sujeito tomando por base a interação do indivíduo com uma estrutura faltante.

O francês parte de duas qualificações dessa estrutura: ele denomina a primeira de estruturação, ou ação da estrutura e a segunda parte se trata da subjetividade, que se encontra submetida na ação (MILLER, 1971).

A estruturação, por sua vez, divide-se em duas ordens contínuas. Estruturante e estruturada, com a primeira indicando movimento e processo enquanto a segunda uma finalização. Na estruturação, ou seja, no momento que se celebra e se desfaz os 
acontecimentos e interações, um elemento se volta contra a ação da estrutura e a significa, a ela se sujeita.

É através dessa relação da estrutura com o sujeito que a virtualidade do estruturante se converte em uma lacuna no real, de forma que passa a suportar uma carência (MILLER, 1971, p. 22). A lacuna decorre do sujeito, da impossibilidade de satisfação de seu desejo ou de um objeto que possa suprir tal falta. Em decorrência disso, Miller explana sobre a necessidade de uma formação imaginária que possa suturar essa ausência.

Além das considerações acima, Miller sugere uma imagem dessa estrutura delineada a partir da distinção, na cadeia de significantes, entre tempo circular e linear. Elabora que "ao cruzar o discurso lógico em seu ponto de menor resistência, o de sua sutura, você pode ver articulada a estrutura do sujeito como uma 'oscilação em eclipses', como o movimento que abre e fecha o nome, e entrega a falta na forma do 1 a fim de aboli-la no sucessor" (1966, parágrafo 40$)^{4}$. Assim, se a enunciação do significante é limitada pela linearidade da cadeia, a significação do que isso representa é circular (MILLER, 1971).

Para um melhor esclarecimento, a estrutura situa a experiência do sujeito e tal relação é circular na medida que ambos devem ao outro a sua definição, ao mesmo tempo que são diferentes, inconcebíveis sem uma função imaginária de desconhecimento, que se destaca como ponto impróprio da estrutura. (MILLER, 1971).

Dentro da noção de desconhecimento reúne-se a percepção, a ideologia e a sensibilidade (MILLER, 1971, p. 29). O discurso do sujeito é um lugar de desconhecimento, pois o sujeito recebe o discurso que emite e o inverte, fazendo-o em primeira pessoa, uma causalidade metonímica. Entende-se assim que através do imaginário o sujeito se faz agente, recebendo o discurso, mas o tomando como seu, ou seja, atua.

A alienação aqui não é entendida somente como um aspecto negativo e corruptível da pretensa verdade, mas como traço essencial para a possibilidade de ser. A causalidade estrutural do sujeito toma o efeito pela causa ${ }^{5}$, sendo esta a lei fundamental da ação da estrutura, que como dito anteriormente, engloba a subjetividade (MILLER, 1971, p. 34).

\footnotetext{
${ }^{4}$ Conforme tradução livre do original: "A traverser le discours logique au point de sa plus faible résistance, celui de sa suture, vous voyez articulée la structure du sujet comme 'battement en éclipses', tel ce mouvement qui ouvre et ferme le nombre, délivre le manque sous la forme du 1 pour l'abolir dans le successeur.".

${ }^{5}$ Michel Pêcheux, sob o pseudônimo Thomas Herbert, trabalha no mesmo sentido postulando que "[...] la estructura invierte causa y efecto a los 'ojos' de los sujetos-suportes de la misma”. O sujeito atua, assim, como um disruptor ideológico que significa o imaginário ao tentar normalizá-lo.
} 
Lacan já havia trabalhado a possibilidade de existência de um imperativo que impele o sujeito a assumir a própria causalidade. Mas qual a posição do sujeito em relação a esta crença? Em sua constatação, a partir da estrutura, parece haver um reconhecimento primário, uma admissão fundamental desse papel derivado simbolizado no Nome-do-pai. (MILLER, 1987, p. 8). Miller defende a existência desse -sim fundamental-, dessa aceitação de algo que interpela e relaciona o homem à estrutura.

\subsubsection{O Outro}

Um ponto que se comunica com a noção de estrutura é a coordenação do sujeito do inconsciente ao discurso do 'Outro'. Este Outro representa não um indivíduo, mas um lugar na estrutura de transferência do saber do sujeito. O Outro é o lugar em que se situa a cadeia do significante que comanda tudo que vai "presentificar-se" do sujeito, é o campo onde o sujeito tem que aparecer (LACAN, 2008, p.200).

Também pode ser definido como um conjunto de possibilidades do que não está contido no sujeito, apesar de se referir a ele (MILLER, 1981, p. 147). O lugar do Outro é onde vem a ser dito o que é imanente ao ser, onde "o mundo é reconfigurado pela cena segundo as leis do significante" (MILLER, 2004a, p. 17). O autor também declara que:

\footnotetext{
É esse saber não sabido, essencialmente inconsciente, chamado aqui de 'sujeito', que se encontra na base da transferência. Entendemos que é por isso que na fórmula 'sujeito suposto saber', não há referência nominal ao Outro, já que o termo 'sujeito' comporta essa dimensão. (...). Esse é o 'erro subjetivo' inaugural da transferência, que conduz o sujeito rumo a uma apropriação de seu próprio dito. Não é apenas o sujeito que está em questão na experiência analítica, no fazer pela palavra, mas também, e sobretudo, o Outro, do qual ele vem falar, a partir de seu posicionamento subjetivo. (MILLER, 1987, p. 77).
}

A partir dos trabalhos de Freud, Lacan entende que no lugar do desejo inconsciente o Eu deve advir, na linguagem, de tal maneira que o sujeito se projeta e se relaciona no discurso do Outro para engajar a fala, momento de criação do desejo. Logo, do que parece indicar o desejo como constitutivo do ser do sujeito, Miller extrai a consideração ontológica de que ser é o desejo.

Para o autor, a presença do significante da mãe convoca o que ele chama de enigma do desejo do Outro, que: "Idealizado, é inflado pela imagem não-negativada do falo materna, cuja consequência é o apego do sujeito a sua resposta fantasmática” (MILLER, 1995, p. 21). 
Lacan trabalha a figura do Nome-do-Pai justamente como esse lugar que não é objeto real e tampouco ideal, mas simbólico, em que "a função do pai no complexo de Édipo é ser um significante que substitui o primeiro significante introduzido na simbolização, o significante materno" (LACAN, 1999, p. 180). Nesta operação, a relação com o significante é fomento da repressão ao desejo de ser e constitui o sujeito. O efeito sujeito atua na defesa ao 'falta-a-ser'.

Não existe outro que possa satisfazer por completo o sujeito. Na clínica, o desvanecimento da demanda é um consentimento à castração, pois " $\mathrm{Na}$ medida em que o sujeito se suporta no Outro, se suporta naquilo que pede ao Outro, o que aparece do lado do Outro como desvanecimento - não existência - aparece do lado do sujeito como destituição.” (MILLER, 1995 p. 31-32).

Mas seria possível viver sem o Outro? Miller fala que essa postura geraria um cinismo da impossibilidade de não existência. Por isso, esclarece que Lacan já delineava a importância de recompor um grande Outro de suplência, para evitar a pulsão, a conexão pura do simbólico e do real que sem a interposição imaginária poderia causar graves problemas (MILLER, 1995).

\section{A LINGUAGEM NO PROCESSO DE IDENTIFICAÇÃO DO SUJEITO}

O sujeito da psicanálise é concebido como efeito da linguagem, o que modifica a articulação cartesiana entre ser e pensamento: de um penso logo sou para um eu sou onde não penso e penso onde não sou. Com isso em consideração, é possível então falar dos processos de alienação e separação do sujeito, em sua formação, para com o Outro. (BARTIJOTO; TFOUNI e CHIARETTI, 2019, p. 8).

Se a psicanálise deve se constituir como ciência do inconsciente, convém partir de que o inconsciente é estruturado como uma linguagem ${ }^{6}$ (LACAN, 2008, p.199) e o sujeito, servo da linguagem, também se demonstra como servo de um discurso em cujo movimento universal seu lugar já está inscrito em seu nascimento, nem que seja sob a forma de seu nome próprio (LACAN, 1998, p.498).

\footnotetext{
${ }^{6}$ Lacan foi equivocadamente caracterizado como estruturalista em razão dessa afirmação, mas cabe dizer que a associação feita por ele não deve ser tomada no sentido estruturalista. Na estrutura em jogo na linguística, tratase de uma estrutura de exclusão do sujeito, ao passo que na psicanálise, trata-se de uma estrutura de inclusão do sujeito. Deste modo a assertiva lacaniana deve ser compreendida à luz da afirmação de que o inconsciente é o discurso do Outro, por meio da qual se depreende a necessária referência à fala, ao discurso do sujeito e ao Outro enquanto lugar de absoluta alteridade dos significantes (COUTINHO JORGE, 2005, p.70).
} 
Para a psicanálise, o processo de constituição subjetiva está intimamente relacionado com a concepção de que o campo do sujeito é efeito, em especial, da linguagem e de uma trama de relações pré-existentes ao nascimento, constituindo o que será o mito fundador de uma história singular. Lacan aponta, inclusive, a existência de um sistema de relações préexistentes ao sujeito e de uma ordem significante que o antecede, pois o Outro que lhe precede está já tomado pela linguagem (TOREZAN; AGUIAR, 2011, p. 538).

Para pensar na questão do inconsciente estruturado como linguagem é importante desdobrar, como já fizemos no capítulo anterior, o inconsciente de origem freudiano e a continuidade lacaniana. Ainda, é importante entender a estrutura como base de sustentação conceitual de uma prática, do real da clínica.

A filiação lacaniana ao estruturalismo ocorre pela busca em resolver problemas sobre o reconhecimento do sujeito que não se encontra incluso no quadro estruturalista. Isto porque o fundamento do estruturalismo consiste em mostrar como o verdadeiro objeto das ciências humanas não é o homem enquanto centro intencional da ação e produtor do sentido, mas as estruturas sociais que lhe determinam (SAFATLE, 2018, p. 45). O que se observa, em princípio, nas teorias estruturalistas é a inadequação do sujeito como agente e a sua consequente caracterização como suporte de estruturas que agem em seu lugar.

A linguística, por exemplo, não comportava o sujeito senão como mero reprodutor do seu verdadeiro objeto, a língua e os elementos que a compõem. A crítica feita por Lacan à teoria linguística foi justamente a exclusão do sujeito e a sua relegação como mero instrumento da língua. Isso, como se os sujeitos não falassem, mas fossem falados pela linguagem, como se eles não agissem, mas fossem agudos pelas estruturas sociais (LEVISTRAUSS, 2004, p. 31).

Ao introduzir a categoria da falta na cadeia significante e, a partir do conceito saussuriano da língua como sistema de valores diferenciais, reelabora a noção de sujeito fora da conotação ontológica que implica na alternativa de um sujeito pleno do humanismo ou a morte do sujeito (COUTINHO JORGE, 2005, p.70). Lacan aponta que o sujeito é inconsciente e o inconsciente não é só linguagem, o inconsciente é mais que o significante. $\mathrm{O}$ objeto da psicanálise é o (a). O inconsciente possui formas de manifestação, dentre elas a linguagem. Mas, também, há o chiste, os sonhos. Ele (inconsciente) se manifesta de modo semelhante em todos os seres humanos. Todo mundo sonha, todo mundo esquece aquilo que sabe, todo mundo faz sintoma. 
Foi a partir do trabalho de Ferdinand de Saussure que Lacan elucidou as teses freudianas sobre o inconsciente para demonstrar que Freud, num só ato, antecedeu e ultrapassou sua elaboração. Saussure introduz sua noção de signo linguístico pela concepção de uma unidade indissociável entre o significante (imagem acústica) e o significado (conceito), tal como dois lados de uma folha de papel, sem que fosse possível falar de um independente do outro. Essa relação entre significante e significado em Saussure não é necessária, mas arbitrária e a sua arbitrariedade reside em seu caráter convencional, que pode ser exemplificado pela existência de inúmeras línguas que designam os mesmos conceitos por meio de diferentes sons. (COUTINHO JORGE, 2005, p.76).

O surgimento da disciplina linguística dá-se, como acontece com toda ciência no sentido moderno, no momento constitutivo de um algoritmo que a funda. Esse algoritmo é o representado por $[\mathrm{S} / \mathrm{s}]$, que se lê: significante sobre significado, correspondendo o " sobre" à barra que separa as duas etapas. A formalização do S/s caracteriza-se, na diversidade das escolas, a etapa moderna da linguística, e a temática dessa ciência, por conseguinte, está efetivamente presa à posição primordial do significante e do significado, como ordens distintas e inicialmente separadas por uma barreira resistente à significação (LACAN, 1998, p. 500).

O significante de fato entra no significado, ou seja, de uma forma que, embora não seja imaterial, coloca a questão de seu lugar na realidade. O algoritmo $\mathrm{S} / \mathrm{s}$, na medida em que ele mesmo é apenas pura função do significante, só pode revelar uma estrutura de significante nessa transferência. Ora, a estrutura do significante está em ele ser articulado.

O que essa estrutura da cadeia significante revela é a possibilidade, justamente na medida em que a língua é comum com outros sujeitos, isto é, em que essa língua existe, de servir-se dela para expressar algo completamente diferente do que ela diz. E aí Lacan aponta para a função mais digna de ser enfatizada na fala: a possibilidade de, por meio dela, disfarçar o pensamento (quase sempre indefinível) do sujeito: a saber, a de indicar o lugar desse sujeito na busca da verdade (LACAN, 1998, p. 505).

Lacan isola na descoberta freudiana do inconsciente aquilo que denomina de primazia do significante para o sujeito e, assim, inverte o algoritmo do signo linguístico saussuriano, A linha que em Saussure designava relação entre significado e significante, adquire em Lacan um valor próprio, o de uma barra de separação resistente à significação. A barra separa o significante de seu efeito de significado e constitui a principal das funções de 
corte do discurso (COUTINHO JORGE, 2005, p.81). Se para Saussure o sentido provém do valor oposicional entre os diversos signos, para Lacan, trata-se, no advento do sentido, da inclusão do sujeito representado entre significantes.

Nesse sentido, o sujeito da análise é constituído por sua própria entrada no dispositivo em que é completado por um psicanalista, que ocupa o lugar do Outro, pontuando seu discurso e lhe confere sentido. $\mathrm{O}$ inconsciente deve ser identificado nas descontinuidades do discurso ou nos capítulos que faltam da história cristalizada dos sintomas que aguardam a decifração (ZAFIROPOULOS, 2018, p.228).

Por isso, diz-se a clínica lacaniana operante por meio da reorientação da palavra do sujeito, porque a linguagem, antes de significar algo, significa para alguém (LACAN, 1998, p. 86). Toda fala tem um endereçamento, entonação, estilo que indicam como ela é direcionada à imagem de um certo outro que sempre é carregado consigo. A fala já traz em si a figura do seu ouvinte ideal e a análise começa a partir de um não agir calculado do analista que permite a projeção dessas imagens no interior da relação analítica (SAFATLE, 2018, p. 40) .

\section{O SUJEITO DA PSICANÁlise CONFRONTADO PELO MUNDO DO TRABALHO E DA MERCANTILIZAÇÃO}

Com a quantificação da vida e o capital alçado ao status de realização do significante-mestre da unificação (MILLER, 2004a), aumenta-se a demanda por avaliação, desejo de controle, busca hedonista pelo consumo e internalizações utilitaristas na sociedade. A absolutização do mercado acaba operando uma reestruturação do sujeito, que efeito, desencadeia uma sociedade cada vez mais instável, ditada pela pretensa imparcialidade da técnica econômica e do apequenamento do valor-trabalho.

Desde os momentos iniciais, o indivíduo está em um lugar de objeto do desejo alheio, incorporando e se diferenciando do meio, forcluindo para a construção de si. Judith Butler (2019) concebe o sujeito como categoria linguística, lugar-tenente e estrutura em formação. Seu estudo explicita a existência de uma esfera psíquica no poder que se volta contra si, constatando assim que o sujeito é efeito desse recuo.

A autora, apoiada no trabalho de psicanalistas, considera ainda que a criança nasce vulnerável à subordinação e à exploração. Tal paixão primária condiciona a formação política e a regulação dos sujeitos, o que coloca a subordinação como imprescindível para o 'vir a ser do sujeito' (BUTLER, 2019, p. 16). Ademais, o desejo de sobrevivência revela outro traço da 
subordinação, o desejo pela sujeição para existir continuamente enquanto sujeito, logo a formação do sujeito da psicanálise leva em consideração essa ambivalência de subordinação e domínio.

Ao transpor as noções mencionadas para a dinâmica do mundo globalizado, com suas linguagens e tecnologias operando ininterruptamente, pode-se vislumbrar como o trabalhador é levado a assumir a servidão diante do desejo do mestre como marca de liberdade. Uma sociedade que fomenta o consumo como marco de uma individualidade de sucesso reproduz tal submissão nas propriedades do trabalho.

Emerge assim uma sociedade de obediência, transfigurada pela noção evasiva do mercado, mas que guarda em si o cerne do comando e da exploração da carência e necessidade do outro. Tal captura ocorre justamente pela manipulação da pulsão vital do amor e da fome, correspondentes às dependências alimentares e sociais (BESSA, 2017, p. 174).

Os modelos de produção integram tal estrutura de formação e direcionam o sujeito para uma aproximação ao ideal do Outro (ZANIN, 2016, p. 105). Por outro lado, ainda permanece os desejos e sentimentos recalcados, uma transformação da atividade em esquizofrenia de si para consigo mesmo, que faz e produz. Eis o sujeito confrontado e constituído pela mercantilização do mundo do trabalho.

A precarização do trabalho também é transpassada pela linguagem, a exemplo das incoerências encontradas entre o animus de proteção legal e os padrões de trabalho real, que ajudam as instituições a proliferar áreas sem lei ou que causam confusão e instabilidade (AZAÏS, 2019, p. 155),

A partir de tais considerações talvez seja o momento de refletir sobre a chamada 'desidentificação' do sujeito em relação aos parâmetros que o engendram ao capital. Como delinear o sujeito do trabalho dissidente das referências dominantes quando este constantemente tem isolado seus sentimentos da força do trabalho contratada, submetido ao recalque para futuramente gozar o desejo de liberdade após receber o salário? (BESSA, 2017, p. 200). Além disso, a psicanálise pode ser uma via de formação do novo sujeito do trabalho, considerando que não dará respostas prontas, idealizadas em planos políticos?

Conforme Butler (2019), o sujeito é considerado como lugar de ambivalência, pois ao reiterar as condições de poder, temporaliza as estruturas e torna possível uma modificação no plano do devir. Neste lugar, a aparência de poder se desloca e se inverte, com o sujeito derivando sua ação de oposição, assim, o desejo pela sujeição para a existência social e da 
vulnerabilidade primária para com o Outro, que é tão explorado pelo poder regulador, não é determinista e gera poder, resistência, em suma, novos sujeitos.

Guattari e Rolnik defendem uma revolução molecular, ou seja, modificações subjetivas de forma multinível $(1999$, p. 37). Os autores advertem que singularização não é o mesmo que individualização, pois enquanto esta ressalta o indivíduo seriado, engajando culpabilização e entrada na lei dominante, o 'agenciamento da subjetivação' buscará o singular, não passível de totalização (GUATTARI; ROLNIK, 1999, p. 31). Mas Butler (2019) promove o chamado ao afastamento da lei por meio da capacidade de ação e disposição a nãoser, a agir para superar as condições de seu surgimento.

Ressalta-se, de qualquer modo, que o sujeito da psicanálise é trabalhado a partir da responsabilidade e da verificação de quais são as amarras idealizadas que o diminuem. Resistir à nivelação da subjetividade dentro do método clínico, antes, é um movimento que aborda o sujeito como categoria ética (MILLER, 1981, p. 221).

Miller assevera que "A psicanálise proporciona ao sujeito um novo ponto de partida. Como? Destituindo suas identificações, devolvendo ao sujeito seu vazio primordial encoberto pelo discurso do mestre" (2004b, p. 21). A atuação psicanalítica, assim, opera-se por meio do corte, no processo de orientação após o fracasso da via do mestre.

\section{O PARADIGMA DO SUJEITO DA PSICANÁlISE NA REFLEXÃO NORMATIVA DA PROTEÇÃO AO TRABALHADOR}

O artigo $7^{\circ}$ da Constituição Federal de 1988 traz uma série de direitos constitucionais dos trabalhadores. Além disso, o Direito do Trabalho pressupõe uma série de princípios que servem inclusive como fonte formal de interpretação e de aplicação do direito. O princípio da proteção, por exemplo, busca sanar as desigualdades decorrentes da realidade estrutural e da condição de hipossuficiência do empregado face ao empregador, fornecendo inegáveis garantias ao trabalhador.

No entanto, a proteção conferida pelos princípios basilares do Direito do Trabalho e pelos os direitos previstos na Constituição aos trabalhadores não é eficiente ao propósito que lhe foi proposto. O problema é constatado não apenas pela ineficiência do ordenamento em garantir proteção e de trabalho digno aos trabalhadores pelo país. A constatação advém, a partir da narrativa aqui já exposta, de um sujeito trabalhador que teve suprimida a sua subjetividade e, portanto, o seu mecanismo de expressão: a fala. 
Antes de adentrar na reflexão objetivada neste derradeiro capítulo, é importante notar que os princípios do Direito do Trabalho mencionados surgem a partir de um paradigma e de uma margem de interpretação do direito característica ao século XX.

O paradigma utilizado nas construções jurídicas do último século, e que vige atualmente no país, é o do sujeito moderno, que culmina no entendimento do sujeito de direito. É com a modernidade que o direito passa a ser atribuído ao indivíduo e a subjetividade jurídica emerge. Subjetividade que no direito traduzia-se na titularidade de direitos que vai além dos bens patrimoniais, como direitos à segurança, a um mínimo de dignidade para se sobreviver em sociedade. A partir do estabelecimento do sujeito de direito, e o movimento de ascensão do sujeito de direito passa a reorientar do Direito no sentido da repersonalização orientando-se pelo princípio da dignidade humana, como alternativa à patrimonialização.

As normas contidas no art. $7^{\circ}$ da Constituição Federal objetivam a melhoria da condição social do trabalhador, esboçando a proteção da relação empregatícia. No entanto, essa proteção destina-se objetivamente ao trabalhador urbano ou rural que se encontra na relação empregatícia que se presente proteger. E a caracterização desse trabalhador é dada por com conjunto de elementos objetivos, disposto no art. $3^{\circ}$, da CLT, que determina que empregado é a pessoa física que presta serviços de natureza não eventual, de forma onerosa e subordinada ao empregador.

O que se pretende não é questionar a existência de proteção constitucional ao trabalhador, tampouco questionar os princípios de proteção ao trabalhador. A reflexão a que se pretende é sobre a possibilidade, a partir da identificação do sujeito da psicanálise e da influência dessa descoberta na análise do papel do sujeito no trabalho, de uma abertura epistemológica no campo normativo do direito do trabalho que aceite e discuta e deixe falar o sujeito trabalhador.

Se a teoria lacaniana a respeito do processo de alienação do sujeito pode ser utilizada como chave de leitura para a compreensão do lugar da relação do sujeito com seu trabalho (ZANIN, p. 103), o movimento a ser feito nesse esforço teórico é o da defesa do '(des)sequestro da subjetividade' do trabalhador. Esse movimento deve ser feito para determinar o rompimento com o processo da "escolha forçada" no qual o sujeito está em processo de repetição com o seu trabalho e que impele o sujeito trabalhador à tentativa frustrada de atender demandas de produção inatingíveis, o que gera o seu retraimento, adoecimento e sequestro de sua subjetividade. 
Apesar de termos um corpo robusto de proteção social ao trabalho disposto na Constituição Federal e em esparsas normas celetistas, dispomos de parcos instrumentos de interpretação do direito, das normas e da realidade do trabalho sob a escuta de um sujeito que fala. Sujeito que foi compelido a calar-se por uma sociedade de obediência, mas como já destacado anteriormente do texto de Carlos Bessa, sujeito que guarda em si o cerne do comando e da exploração da carência e necessidade do outro.

Se o sujeito confrontado e constituído pela mercantilização do mundo do trabalho ainda permanece com os seus desejos e sentimentos recalcados, a luta necessária deve ser para a emancipação do sujeito da psicanálise como paradigma destinado à reflexão, desconstrução e construção de uma interpretação do direito do trabalho pelo desejo do Sujeito trabalhador.

\section{CONSIDERAÇÕES FINAIS}

Ao tomar por base a relação entre o inconsciente e a linguagem, mostrou-se necessário argumentar que a linguagem jurídica padrão, enquanto integralizadora da estrutura, exclui o sujeito do inconsciente da sua estruturação, tomando-o como um elemento separado, passível de reproduzir a sujeição que os identificadores jurídicos - objetivos - criam.

Assim, o sujeito do direito reproduz uma divisão fictícia entre trabalho autônomo e subordinado ou a categorizações que destoam das formas reais de interação, de forma que a linguagem jurídica é elementar para a formação de uma vida subordinada aos desníveis da vida mercantilizada.

Refletir sobre as formas de orquestramento da subjetivação do sujeito trabalhador exige novas metodologias que atuem nessa lacuna, que ouçam o que tem algo a falar. Imersos na sociedade da totalização do espaço/tempo, apoiada na crença binária do ser e não-ser, é difícil equalizar concepções que em contrapartida ao entendimento dominante, atuem nessa fissura descontínua, que reconheçam as ausências de ausências na estrutura da ciência jurídica e questionem caminhos diferentes para o sujeito ali submetido.

Pertinente recordar que a psicanálise foi concebida a partir da consideração do elemento ignorado da ciência, o inconsciente, pugnando formas de viabilizar, através da clínica, a singularidade do homem apoderado de identificadores.

Por isso, o percurso deste texto começou com o momento da 'descoberta' do inconsciente, do desejo de ser, da relação do sujeito com o Outro e com a estrutura, para então, com base na clínica e na multiplicidade potente da linguagem narrar uma outra via de 
entendimento do sujeito do trabalho, atento a uma responsabilidade ética de tratativa, conforme os estudos de Jacques-Alain Miller e de outros pesquisadores do sujeito da psicanálise.

Em um contexto de precarização do trabalho e de predomínio aritmético, que atua enquanto poder normalizador, desvincular-se dos significantes dominantes na esfera jurídica e lidar com a cicatriz da falta é uma forma de vislumbrar o sujeito do advir, que antes de ser uma pedra de inquietação na pesquisa, é o próprio caminho para uma real proteção ao trabalho.

\section{REFERÊNCIAS}

AZAÏS, Christian. Figures émergentes. In: BUREAU, Marie-Christine et al (directeurs). Les zones grises des relations de travail et d'emploi: Un dictionnaire sociologique. Buenos Aires: Teseo, 2019.

BARTIJOTO, Juliana; TFOUNI, Leda; CHIARETTI, Paula. Wo Es war, soll Ich werden: Traduções e Consequências Teóricas. Universidade de Fortaleza - Revista Subjetividades, vol. 19, núm. 3, 2019.

BESSA, Cesar. Além da subordinação jurídica no direito do trabalho. São Paulo: LTr, 2017.

BUTLER, Judith. A vida psíquica do poder: teorias da sujeição. Trad: Rogério Bettoni. Ed. Autêntica: Belo Horizonte, 2019.

COUTINHO JORGE, Marco Antonio. Fundamentos da psicanálise de Freud a Lacan, v.1: as bases conceituais. Rio de Janeiro: Jorge Zahar Ed., 2005.

GUATTARI, Félix; ROLNIK, Suely. Micropolítica: cartografias do desejo. $4^{\mathrm{a}}$ ed. Vozes: Petrópolis, 1996.

LACAN, Jacques. O seminário, livro 5: Formações do inconsciente. Rio de Janeiro: Jorge Zahar, 1999.

Escritos. Rio de Janeiro: Jorge Zahar, 1998.

, Seminário livro 11: os quatro conceitos fundamentais da psicanálise. $2^{\mathrm{a}}$ ed. Rio de Janeiro: Jorge Zahar, 2008.

Séminaire XXIII. Paris: Seuil, 2005.

LÉVI-STRAUSS, Claude. O cru e o cozido. São Paulo: Cosac Naify, 2004. 
MILLER, Jacques-Alain. La Suture: Éléments de la logique du signifiant. Concept and Form: The Cahiers pour l'Analyse and Contemporary French Thought, v. 1, article 1.3. Paris, 1966. Disponível em: <http://cahiers.kingston.ac.uk/synopses/syn1.3.html>. Acesso em: 25/jan./2021.

Cause et consentement. Cours du 18 novembre. Paris, 1987. Disponível em: $<$ http://jonathanleroy.be/wp-content/uploads/2016/01/1987-1988-Cause-et-consentement-JAMiller.pdf >. Acesso em 25/jan./2021.

. A lógica na direção da cura. Seção Minas Gerais da Escola Brasileira de Psicanálise do Campo Freudiano. Tradução de Lázaro Elis Rosa e outros, 1995.

A era do homem sem qualidades. Opção Lacaniana OnLine. Tradução: Vera Avellar Ribeiro. Originalmente publicado no Quarto $\mathrm{n}^{\circ}$ 82, revista da Escola da Causa Freudiana na Bélgica, 2004a.

Psicoanálisis y Política. $1^{\mathrm{a}}$ ed. Buenos Aires: Grama, 2004b.

La angustia lacaniana. $1^{\mathrm{a}}$ ed. Buenos Aires: Paidós, 2013.

Causa y consentimiento. $1^{\mathrm{a}}$ ed. Buenos Aires. Paidós. 2019.

MILLER, Jacques-Alain; HERBERT, Thomas. Ciencias sociales: ideología y conocimiento. Traducción: Oscar Landi y Hugo Acevedo. Buenos Aires: Siglo Veinteuno, 1971.

SAFATLE, Vladimir. Introdução a Jacques Lacan. 4.ed. Belo Horizonte: Autêntica. 2018.

TOREZAN, Zeila C. Facci; AGUIAR, Fernando. O sujeito da psicanálise: particularidades na contemporaneidade. Rev. Mal-Estar Subj, Fortaleza , v. 11, n. 2, p. 525-554, 2011. Disponível em: <http://pepsic.bvsalud.org/scielo.php?script=sci_arttext\&pid=S1518$61482011000200004 \& \operatorname{lng}=$ pt\&nrm=iso $>$. Acesso em 23/jan./2021.

ZAFIROPOULOS, Markos. Lacan e Lévi-Strauss ou o retorno a Freud (1951-1957). $1^{\text {a }}$ Ed. Rio de Janeiro: Civilização Brasileira. 2018.

ZANIN, Fernanda. Acerca da relação alienada entre sujeito e trabalho na contemporaneidade: um ensaio sob o olhar da psicanálise. Dissertação apresentada ao Programa Pós-Graduação em Psicologia da Universidade Federal do Paraná, UFPR: Curitiba, 2016.

ZIZEK, Slavoj. Como ler Lacan. Tradução: Maria Luiza X. de A. Borges; Revisão técnica Marco Antonio Coutinho Jorge. Rio de Janeiro: Zahar. 2010. 